\title{
ANALISIS PENDAPATAN USAHA BUDIDAYA CACING SUTERA DENGAN MEDIA NAMPAN BERTINGKAT ; KASUS USAHA KELUARGA DI DESA KARANGTEJO KEDU TEMANGGUNG JAWA TENGAH DAN UJI COBA DI BELITANG OKU TIMUR
}

\author{
Muridin \\ Sekolah Tinggi Ilmu Pertanian Belitang \\ Jln.Kampus Pertanian No.3 Belitang Kab.OKU Timur Prov.Sumatera Selatan \\ e-mail: muridin43@gmail.com
}

\begin{abstract}
Abstrak
This research aims to know the techniques of cultivation and silk worm life terms with the media tray multilevel. To calculate the income level of the silk worm cultivation efforts with media in the village-floor tray Karangtejo Kedu Temanggung Central Java as well as key factors for the development of silk worm in Belitang OKU East. Data processing methods used are of financial analysis (cost of production, production, reception, income and RC ratio) and non financial analysis (Bahaninput, Agroklimat, potential market). The research results obtained with silk worm cultivation media tray multilevel can be dikebangkan in the East viewed from the OKU Belitang market potential is great with silk worms requests in one month about 2815 glasses. The available input materials among others, silk worm seed dregs of tofu, chicken manure, fine bran. Temperature suitability trials with cultivation in Eastern silk worm Belitang OKU can adapt and expand the container trays. Production costs incurred in one fell prosesproduksi amounting to Rp 9,256,350, Rp gained acceptance $18,977,000$ and revenue amounting to $\mathrm{Rp} 9,720,650$ with a value of $\mathrm{RC}$ ratio of 2.05.
\end{abstract}

Keywords: Silk Worm Cultivation, Matches, container tray.

\section{PENDAHULUAN}

\section{A. Latar Belakang}

Pakan alami sangat dibutuhkan sebagai sumber makanan ikan karena kandungan dari nutrisinya yang lengkap dibandingkan dengan pakan buatan. Kandungan nutrisi dalam pakan alami belum dapat tergantikan secara keseluruhan oleh pakan buatan( Efendi, 2014). Diantara sekian banyak pakan alami yang ada, salah satunya adalah cacing sutera atau dikenal dengan cacing rambut. Cacing sutera menjadi favorit bagi semua benih ikan dan biasanya diberikan dalam keadaan hidup atau masih segar. Cacing ini cukup mudah dijumpai, terutama di selokan yang mengandung banyak mengandung bahan organik. Selain itu, budidaya cacing sutera juga relatif mudah dibudidayakan, kemampuannya beradaptasi dengan kualitas air yang buruk membuatnya bisa dipelihara di segala jenis perairan yang ada aliran airnya, bahkan pada perairan tercemar sekalipun. Kebutuhan cacing sutera di Kecamatan Belitang masih mengandalkan tangkapan dari alam dengan harga per $250 \mathrm{ml}$ Rp 15.000 - Rp 20.000. Sangat jauh dengan harga cacing sutera hasil budidaya di Desa Karang Tejo Kecamatan Kedu Kabupaten Temanggung dengan harga per $250 \mathrm{ml}$ Rp7000. Mengingat mulai banyaknya petani yang melakukan usaha pembenihan ikan menjadi peluang jika pengembangan cacing sutera dengan media nampan bertingkat dapat dikembangkan di Kecamatan Belitang.

\section{B. Rumusan Masalah}

1.Seberapa besar modal dan pendapatan yang diterima pembudidaya cacing sutera dengan media nampan bertingkat di Desa Karangtejo Kecamatan Kedu Kabupaten Temanggung.
2. Apakah budidaya cacing sutera dengan media nampan bertingkat dapat dikembangkan di Kecamatan Belitang OKU Timur.

\section{Tujuan dan Kegunaan}

1. Untuk mengkaji teknik budidaya dan syarat hidup cacing sutera (Tubifex sp) dengan media nampan bertingkat di Desa Karangtejo Kecamatan Kedu Kabupaten Temanggung untuk dibandingkan di Kecamatan Belitang OKU Timur.

2. Untuk mengkaji tingkat pendapatan dari petani pembudidaya cacing sutera dengan media nampan bertingkat dalam satu kali proses produksi.

Adapun kegunaan dari penelitian ini sebagai berikut

1. Bagi Mahasiswa sebagai sumber informasi tambahan tentang bagaimana teknik budidaya cacing sutera dengan sistem nampan bertingkat di Desa Karangtejo, Kec.Kedu Kabupaten Temanggung Jawa Tengah dan sebagai sumber referensi dan bahan pustaka bagi peneliti selanjutnya.

2. Bagi Petani sebagai promosi pengembangan cacing sutera dengan nampan bertingkat agar dapat dikembangkan di daerah lain.

\section{A. Tinjauan Pustaka}

\section{KERANGKA PEMIKIRAN}

1. Cacing Sutera

Cacing sutera merupakan hewan tingkat rendah karena tidak memiliki tulang belakang yang disebut invertebrate.

\section{Konsepsi Agribisnis}

Agribisnis dapat didefinisikan setiap usaha komersil yang berkaitan dengan kegiatan produksi pertanian yaitu berupa kegiatan sarana produksi (input) pertanian ataupun 
pengusahaan produksi pertanian itu sendiri dan pengolahan hasil (output) pertanian. Oleh sebab itu, agribisnis mencakup keseluruhan kegiatan produktif mulai dari perangkat keuangan, kepegawaian dan pemasaran sampai dengan kecilnya usaha mereka yang bersifat komersil (Sjarkowi dan Marwan,2004)

\section{Konsepsi Penerimaan dan Pendapatan}

Penerimaan usaha dapat diartikan sebagai besaran keseluruhan hasil produksi yang diperoleh dari hasil produksi usaha dan diberikan dengan harga yang berlaku saat ini. Selanjutnya didalam penerimaan usaha tersebut tidak terlepas dari harga dan produk sesuai dengan pendapatan yang mengatakan bahwa harga merupakan salah satu produk dalam pemasaran hasil (Kristianto, 2006).

\section{B. Model Pendekatan}

Pendekatan yang digunakan adalah model:

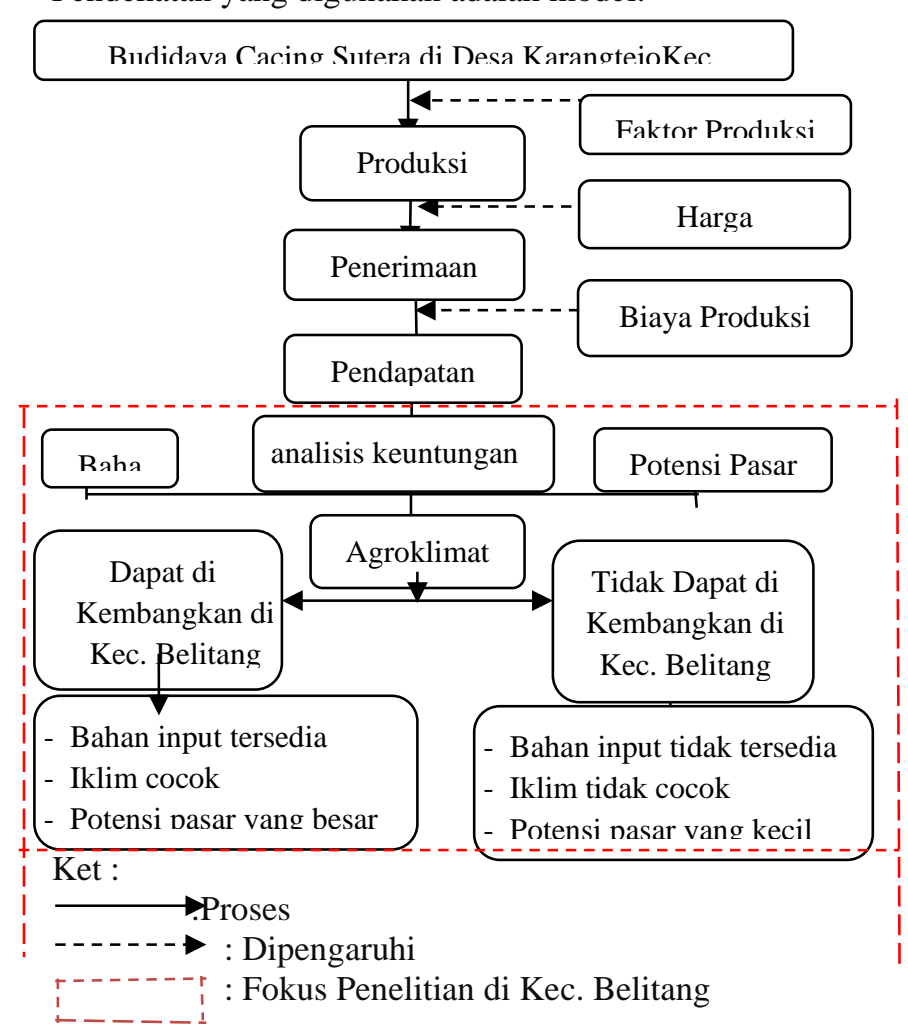

Gambar 1. Model Pendekatan Diagramatik

\section{Hipotesis}

1.Bahwa budidaya cacing sutera dengan media nampan bertingkat dapat dikembangkan di Kecamatan BelitangOKU Timur.

2. Bahwa biaya yang dikorbankan lebih kecil dari pada penerimaan sehingga memperoleh pendapatan dalam usaha budidaya cacing sutera dengan media nampan bertingkat di Desa Karangtejo Kecamatan Kedu Kabupaten Temanggung

\section{Batasan - Batasan}

1.Responden adalah petani yang mengusahakan budidaya cacing sutera dengan media nampan bertingkat di Desa Karangtejo Kecamatan Kedu Kabupaten Temanggung.

2.Tenaga Kerja yang digunakan adalah petani pembudidaya cacing sutera

3. Biaya Produksi adalah seluruh biaya yang dikeluarkan pada usaha budidaya cacing sutera (Rp/proses)

4. Biaya Tetap adalah biaya yang penggunaannya tidak habis dalam satu kali produksi (Rp)

5. Biaya Variabel adalah biaya yang habis dalam satu kali proses produksi (Rp)

6. Produksi adalah hasil usaha cacing sutera gelas/250ml)

7. Penerimaan adalah hasil perkalian antara produksi dari budidaya cacing sutera dengan harga jual yang berlaku (Rp)

8. Pendapatan adalah Penerimaan dikurangi dengan total biaya produksi $(\mathrm{Rp} /$ proses ).

9. Lama produksi adalah 1 tahun dimana 2 bulan pertama merupakan proses produksi.

10. Bibit cacing sutera merupakan tangkapan dari alam yang sudah dikarantina.

11. Harga cacing sutera per gelas ukuran $250 \mathrm{ml}$ adalah Rp 7.000

12. Uji coba budidaya cacing sutera di Kecamatan Belitang sebatas cacing sutera dapat beradaptasi didalam wadah nampan.

\section{METODE PENELITIAN}

\section{A. Tempat dan Waktu}

Penelitian dilaksanakan Kec. Belitang Kabupaten OKU Timur. Penelitian ini telah dilaksanakan pada bulan Desember 2017 sampai bulan Februari 2018.

\section{B. Metode Penelitian dan Metode Penarikan Contoh}

Metode penelitian yang digunakan adalah studi kasus pembudidaya cacing sutera dengan media nampan bertingkat di Desa Karangtejo Kecamatan Kedu Kabupaten Temanggung.

\section{Metode Pengumpulan Data}

Data yang dikumpulkan meliputi data primer dan data sekunder.Pengumpulan data primer dilakukan dengan pengamatan di lapangan dan wawancara secara langsung dengan petani pembudidaya cacing sutera dengan media nampan bertingkat. Data sekunder diperoleh dari literature dan instasi / lembaga terkait.

\section{Metode Pengolahan Data}

Pengolahan data yang sudah ditabulasi dianalisis sebagai berikut.

1. Biaya Produksi menggunakan rumus

$$
\mathrm{TC}=\mathrm{FC}+\mathrm{VC}
$$

Dimana :

TC $=$ Total Cost $\quad(\mathrm{Rp})$

$\mathrm{FC}=$ Fixed Cost $(\mathrm{Rp})$

$\mathrm{VC}=$ Variabel Cost $(\mathrm{Rp})$

2. Penerimaan menggunakan rumus:

$\mathrm{R}=\mathrm{Y} \quad \mathrm{X} \quad \mathrm{P}$ 
Dimana

$\mathrm{TR}=$ Total Revenue (Rp)

$\mathrm{Y}=$ Output Produksi (liter)

$\mathrm{P}=$ Price $(\mathrm{Rp})$

3. Pendapatan menggunakan rumus :

$$
\begin{aligned}
& \mathrm{I}=\mathrm{TR}-\mathrm{TC} \ldots \ldots \ldots \ldots . . . . . . . \\
& \text { Dimana }: \\
& \mathrm{I}=\text { Income }(\mathrm{Rp}) \\
& \mathrm{TR}=\text { Total Revenue }(\mathrm{Rp}) \\
& \mathrm{TC}=\text { Total Cost }(\mathrm{Rp})
\end{aligned}
$$

4. Untuk menghitung tingkat keuntungan yang akan diperoleh menggunakan rumus:

$$
\begin{aligned}
\mathrm{R} / \mathrm{C}= & \frac{\text { Revenue }}{\text { Total Cost }} \ldots \ldots \ldots \ldots \\
\text { Dimana: } & \mathrm{R}=\text { Revenue } \\
& \mathrm{C}=\text { Total Cost }
\end{aligned}
$$

\section{HASIL DAN PEMBAHASAN}

\section{A. Profil Usaha Budidaya Cacing Sutera}

Budidaya cacing sutera dengan menggunakan wadah nampan bertingkat merupakan terobosan baru yang ditemukan oleh pembudidaya Cacing sutera. Budidaya dengan menggunakan nampan ini sangat cocok dilakukan bagi pembudidaya yang memiliki keterbatasan lahan.misalnya didaerah kota. budidaya ini dapat memanfaatkan pekarangan samping rumah yang sempit, karena nampan yang digunakan disusun vertikal sesuai dengan keinginan sehingga mampu menampung banyak nampan. Budidaya Cacing sutera ini menggunakan sirkulaisi air yang berputar. Sistem ini bukan hal baru lagi dalam dunia perikanan, sistem ini pada dasarnya mengolah dan menggunakan kembali air yang sudah dipakai pengisian air dari luar hanya dilakukan untuk mengganti air yang berkurang akibat kebocoran ataupun evaporasi.

\section{B. Syarat Hidup Cacing Sutera}

Habitat dan penyebaran cacing sutera banyak ditemukan di daerah tropis.dengan dasar perairan yang disukai oleh cacing sutera ini adalah berlumpur yang mengandung banyak bahan organik. Karena makanan utamanya bahan - bahan organik yang telah terurai dan mengendap di dasar perairan. Cara makan cacing ini dengan menenggelamkan kepalanya kedalam lumpur dan ekornya akan diatas permukaan lumpur untuk bernafas.Kebiasaan hidup dari cacing sutera ini dengan menggerombol atau membentuk koloni.cacing ini dapat dilihat karena berwarna merah dipermukaan lumpur, warna merah pada cacing sutera menandakan cacing sutera siap untuk diambil.

\section{Proses Budidaya Cacing Sutera}

\section{Sarana dan Prasarana}

\section{a. Alat dan Bahan Produksi}

1.Bibit Cacing Sutera yang digunakan dalam budidaya cacing sutera sebanyak 16 gelas untuk mencukupi nampan sebanyak 400 buah.
2. Kotoran Ayam dalam budidaya cacing sutera dalam satu kali proses produksi sebanyak $766 \mathrm{~kg}$ dengan rincian pembuatan substrat sebanyak $240 \mathrm{~kg}$, pembuatan pakan sebanyak $260 \mathrm{~kg}$, pembuatan pupuk sebanyak $266 \mathrm{~kg}$.

3. Ampas Tahu cukup mudah didapat dengan harga yang relatif murah dan merupakan sumber makanan untuk cacing sutera yang digunakan dalam satu kali proses produksi sebanyak $220 \mathrm{~kg}$ dengan rincian untuk pembuatan substrat sebanyak $80 \mathrm{~kg}$ dan untuk pembuatan pakan sebanyak $140 \mathrm{~kg}$.

4.Dedak Halus.Penggunaan dedak dalam budidaya cacing sutera dengan media nampan bertingkat dalam satu kali proses produksi sebanyak $220 \mathrm{~kg}$ dengan rincian pembuatan substrat sebanyak $80 \mathrm{~kg}$ dan pembuatan pakan sebanyak $140 \mathrm{~kg}$.

5. Lumpur. Penggunaan lumpur dalam budidaya cacing sutera dengan media nampan bertingkat sebanyak 800 liter untuk nampan 400 buah.

b. Proses Budidaya

1. Pembuatan Rangkaian Rak.

a. Rak bertingkat dibuat dari Kayu kaso dan reng. Jarak antara tingkat atas dan tingkat bawah yaitu $25-30 \mathrm{~cm}$. dalam satu rak nantinya memuat 54 nampan, baris kesamping diisi 9 nampan dan baris kebawahnya diisi 6 nampan.

b. Setelah rangkaian rak terbentuk, nampan yang akan dipakai dalam budidaya cacing sutera dilubangi dengan solder dengan tinggi 7 dan 8 cm dari dasar nampan. banyaknya lubang 6 buah, 3 buah pada ketinggian $7 \mathrm{~cm}$ dan 3 buah pada ketinggian $8 \mathrm{~cm}$.

c.Susun semua nampan yang akan digunakan. nampan yang paling atas lubangnya menghadap kearah depan dan nampan dibawahnya lubangnya menghadap kebelakang, begitu juga nampan - nampan dibawahnya.

d. Pasang paralon $1 / 2$ inci disetiap rak dan dipasang diatas nampan bagian atas. lubangi paralon tersebut tepat pada posisi nampan. tujuannya untuk mengalirkan air kesemua nampan bagian atas.

e.Pasang pompa dibagian bawah penampungan air untuk mengalirkan nampan dengan jumlah 400 buah digunakan nampan dengan kapasitas 90 watt.

\section{Persiapan Media}

Proses fermentasi memerlukan waktu minimal 5 hari setelah pencampuran bahan - bahan tersebut.

Adapun proses fermentasi sebagai berikut :

a. Semua media disiapkan untuk kotoran ayam diharuskan dijemur minimal 6 jam di terik matahari. untuk 400 buah nampan memerlukan dedak halus sebanyak $80 \mathrm{~kg}$, ampas tahu $80 \mathrm{~kg}$ dan kotoran ayam sebanyak $240 \mathrm{~kg}$.

b. probiotik yang telah disiapkan kemudian dicampur dengan tetes tebu dan air, semua bahan tersebut diaduk didalam bak dan diaerasi selama 
ISSN : 2598-0521

2 jam untuk mengaktifkan bakteri dalam probiotik

c. Semua media dimasukkan kedalam tong ataupun drum yang telah disiapkan. Tutup wadah tersebut dan didiamkan selama 5 hari.media yang jadi mengeluarkan bau harum seperti bau tape.

d. Media yang difermentasi kemudian dicampur dengan lumpur dan dimasukkan ke dalam nampan dengan ketebalan media $5-7 \mathrm{~cm}$. dan diisi air dengan ketinggian 1- $2 \mathrm{~cm}$. Diamkan media didalam nampan selama 7 hari sampai media tidak mengeluarkan gas.

\section{Persiapan Benih}

Benih cacing sutera yang akan digunakan dalam budidaya sebaiknya dalam keadaan sehat. Apabila benih cacing sutera didapat dari alam sebaiknya dilakukan penangkaran.

4.Penebaran Benih dilakukan dengan memasukkan cacing sutera kedalam baskom kemudian disiram air, koloni cacing sutera akan terurai dan dengan mudah disebar kesemua nampan dengan menggunakan sendok. Waktu penebaran benih yang baik yaitu pagi hari pukul $07.00-08.00 \mathrm{WIB}$ atau sore hari pukul $16.00-17.00$ WIB.

\section{Pemberian Pakan}

Pemberian pakan yang cukup diharapkan untuk memacu pertumbuhan cacing sutera di media budidaya pemberian pakan yang cukup minimal 2 hari sekali sekaligus berfungsi untuk mengembalikan ketinggian awal media agar berada pada ketinggian $7 \mathrm{~cm}$.

\section{Pemeliharaan}

Lama waktu pemeliharaan cacing sutera berkisar 2 bulanan. masa pemeliharaan ini dilakukan dengan mempertimbangkan bahwa daur hidup yang dibutuhkan cacing sutera dari menetas sampai dewasa dan menghasilkan kokon memerlukan waktu 50-57 hari Bahkan sekarang petani pembudidaya mampu panen 6 hari sekali setelah panen perdana yang memakan waktu 2 bulanan.

\section{Panen}

Ciri wadah nampan yang siap untuk dipanen adalah berwarna kemerahan media tersebut dan apabila dipegang media terasa kental karena didalamnya terdapat koloni cacing sutera yang banyak. Panen perdana dilakukan ketika masa pemeliharaan sudah mencapai 2 bulan saat itulah pemanenan dilakukan.Pemanenan berikutnya dilakukan 6 hari sekali setelah panen perdana atau bisa juga panen setiap hari dengan pembagian 400 nampan dipanen selama 6 hari. Jadi untuk panen setiap hari nampan yang dipanen sekitar 66 - 67 mampu menghasilkan 7 gelas atau sekitar $250 \mathrm{ml}$ pergelas dari 66 nampan dengan harga pergelasnya $\mathrm{Rp} 7000$.

\section{F. Analisis Biaya Produksi}

\section{Biaya Produksi}

Dari tabel dapat dijelaskan bahwa biaya penyusutan alat sebesar Rp 2.524.000, sedangkan biaya sewa lahan per tahun ukuran 3x4 meter sebesar Rp 500.000.

Tabel 3. Total Biaya Tetap Usaha Budidaya Cacing Sutera

\begin{tabular}{rlr} 
No & \multicolumn{1}{c}{ Uraian } & Jumlah(Rp/tahun) \\
1 & Penyusutan alat & 2.524 .000 \\
2 & Sewa lahan & 500.000 \\
\hline$\sum$ & & 3.024 .000 \\
\hline
\end{tabular}

Sumber : Hasil Olahan Data Primer, 2018

Total biaya tetap yang dikeluarkan dalam satu kali proses produksi dalam usaha budidaya cacing sutera dengan media nampan bertingkat sebesar Rp 3.024.000,

Tabel 4 . Biaya Variabel Budidaya Cacing Sutera

\begin{tabular}{llr}
\hline No & Uraian & Jumlah (Rp) \\
\hline 1 & Substrat & 530.000 \\
2 & Pakan & 655.500 \\
3 & Pupuk & 146.850 \\
4 & Tenaga Kerja & 4.300 .000 \\
5 & Listrik & 600.000 \\
\hline$\sum$ & & 6.232 .350 \\
\hline
\end{tabular}

Sumber : Hasil Olahan Data Primer, 2018.

Dari tabel dapat dijelaskan bahwa biaya variabel yang dikeluarkan dalam budidaya cacing sutera dengan media nampan bertingkat per proses produksi sebesar Rp 6.232.350.

Adapun total biaya produksi yang dikeluarkan oleh pembudidaya cacing sutera dengan media nampan bertingkat adalah

Tabel 5. Total Biaya Produksi Usaha Budidaya Cacing Sutera

\begin{tabular}{rlr}
\hline No & Uraian & Jumlah (Rp) \\
\hline 1 & Biaya Tetap & 3.024 .000 \\
2 & Biaya Variabel & 6.232 .350 \\
\hline$\sum$ & & 9.256 .350 \\
\hline
\end{tabular}

Sumber: Hasil Olahan Data Primer, 2018.

Dari tabel total biaya produksi budidaya cacing sutera dengan media nampan bertingkat di Desa Karang Tejo Kecamatan Kedu Kabupaten Temanggung sebesar Rp 9.256.350. didapat dari penjumlahan biaya tetap sebesar Rp 3.024.000 dengan biaya variabel sebesar Rp 6.232.350.

\section{Produksi dan Penerimaan}

Dalam satu hari mampu memanen cacing sutera sebanyak 7 gelas dengan ukuran per gelasnya $250 \mathrm{ml}$. Sedangkan penerimaan yang diperoleh dalam satu kali proses produksi usaha budidaya cacing sutera dengan media nampan bertingkat sebesar Rp. 18.977.000. 
Tabel 5 . Produksi Cacing Sutera Dengan Media Nampan Bertingkat

\begin{tabular}{|c|c|c|c|c|c|}
\hline No & Uraian & Vol & Satuan & $\begin{array}{c}\text { Harga } \\
\text { (Rp) }\end{array}$ & $\begin{array}{c}\text { Jumlah } \\
\text { (Rp) }\end{array}$ \\
\hline 1 & ke -3 & 217 & Gelas & 7.000 & 1.519 .000 \\
\hline 2 & ke -4 & 210 & Gelas & 7.000 & 1.470 .000 \\
\hline 3 & ke -5 & 217 & Gelas & 7.000 & 1.519 .000 \\
\hline 4 & ke -6 & 217 & Gelas & 7.000 & 1.519 .000 \\
\hline 5 & ke -7 & 196 & Gelas & 7.000 & 1.372 .000 \\
\hline 6 & ke -8 & 217 & Gelas & 7.000 & 1.519 .000 \\
\hline 7 & ke -9 & 210 & Gelas & 7.000 & 1.470 .000 \\
\hline 8 & $\mathrm{ke}-10$ & 217 & Gelas & 7.000 & 1.519 .000 \\
\hline 9 & $\mathrm{ke}-11$ & 210 & Gelas & 7.000 & 1.470 .000 \\
\hline 10 & ke -12 & 800 & Gelas & 7.000 & 5.600 .000 \\
\hline \multicolumn{5}{|c|}{2711} & 18.977 .000 \\
\hline
\end{tabular}

Sumber : Hasil Olahan Data Primer, 2018

\section{Pendapatan}

Pendapatan yang diterima dalam budidaya cacing sutera dengan media nampan bertingkat sebagai berikut : Tabel 6. Pendapatan Usaha Budidaya Cacing Sutera

\begin{tabular}{rlr} 
No & Uraian & Jumlah (Rp) \\
\hline 1 & Penerimaan & 18.977 .000 \\
2 & Biaya produksi & 9.256 .350 \\
\hline$\sum$ & & 9.720 .650 \\
\hline
\end{tabular}

Sumber : Hasil Olahan Data Primer, 2018.

Dari tabel dapat dijelaskan pendapatan yang diterima oleh pembudidaya cacing sutera dengan media nampan bertingkat sebesar Rp 9.720.650 yang didapatkan dari pengurangan penerimaan sebesar Rp 18.977.000 dengan biaya produksi sebesar Rp. 9.256.350 (Lampiran $10)$.

\section{Analisis Keuntungan}

Untuk mengetahui tingkat keuntungan yang diperoleh dalam budidaya cacing sutera dengan media nampan bertingkat adalah:

Tabel 7. Nilai R/C Ratio

\begin{tabular}{rlr}
\hline No & Uraian & Jumlah \\
\hline 1 & Penerimaan & 18.977 .000 \\
2 & Biaya Produksi & 9.256 .350 \\
\hline & R/C & 2,05 \\
\hline
\end{tabular}

Sumber : Hasil Olahan Data Primer, 2018

Nilai R/C ratio 2,05 maka setiap Rp 1 yang dikeluarkan maka akan memperoleh penerimaan sebesar $\mathrm{Rp} 2,05$ dan usaha budidaya cacing sutera dengan media nampan bertingkat menguntungkan.

\section{G. Analisis Non Finansial}

\section{Potensi pasar}

Permintaaan pasar terhadap cacing sutera yang besar merupakan peluang yang sangat baik.

Tabel 8 . Potensi Pasar dalam Budidaya Cacing Sutera

\begin{tabular}{llll}
\hline $\mathrm{N}$ & Uraian & Di & Di Kecamatan Belitang \\
$\mathrm{o}$ & Karangtejo & \\
\hline
\end{tabular}

\begin{tabular}{cccc}
\hline \multicolumn{3}{c}{ Kec. Kedu } \\
\hline 1 & Potensi & -pembenihan & - pembenihan ikan lele \\
. & pasar & ikan lele & - pembenihan ikan \\
& & -pembenihan & gurame \\
& & ikan hias & - pembenihan ikan patin \\
\hline
\end{tabular}

Sumber: Olahan Data Primer, 2018

Kebutuhan cacing sutera di Kecamatan Belitang didominasi oleh pembenihan ikan. Selama ini cacing sutera masih mengandalkan tangkapan cacing sutera di alam bergantung musim, ketika musim hujan keberadaannya sulit ditemukan karena koloni cacing sutera terbawa arus air hujan dan media atau habitatnya juga ikut rusak. Sehingga pada musim penghujan merupakan waktu sulit untuk mendapatkan cacing sutera dari tangkapan alam.Adapun untuk mendapatkan cacing sutera dari tangkapan alam kita harus terlebih dahulu memesan cacing sutera, karena pencari cacing sutera hanya mampu mendapatkan cacing sutera dalam jumlah terbatas. selain itu, harga yang ditawarkanpun cukup mahal yaitu Rp 15.000 per $250 \mathrm{ml}$. Menurut (Efendi, 2013) diasumsikan dalam setiap satu kali pemijahan ikan lele dihasilkan rata - rata 50.000 ekor benih lele dan jumlah benih lele sebanyak 50.000 membutuhkan cacing sutera sekitar 20 liter.

\section{Bahan Input}

Dalam budidaya cacing sutera dengan media nampan bertingkat ketersediaan bahan baku merupakan hal terpenting, bahan baku merupakan syarat awal dalam pembuatan media atau habitat baru untuk cacing sutera.

Tabel 10 . Bahan Input yang Digunakan dalam Budidaya Cacing Sutera

\begin{tabular}{llll}
\hline No & Uraian & $\begin{array}{c}\text { Budidaya di } \\
\text { Karangtejo } \\
\text { Kec. Kedu }\end{array}$ & \multicolumn{1}{c}{$\begin{array}{c}\text { Uji Coba } \\
\text { Budidaya } \\
\text { di Kec. Belitang }\end{array}$} \\
\hline 1. & Bahan & - Kotoran ayam & -Kotoran ayam \\
& input & - Ampas tahu & - Ampas tahu \\
& & - Dedak halus & - Dedak halus \\
& & - Lumpur & - Lumpur \\
& & -Bibit cacing sutera & -Bibit cacing \\
& & sutera \\
\hline
\end{tabular}

Sumber : Hasil Olahan Data Primer, 2018.

Adapun bahan input yang digunakan dalam budidaya cacing sutera adalah :

a. Bibit Cacing Sutera

Untuk mendapatkan bibit cacing sutera di Kecamatan Belitang yaitu dari tangkapan alam.Bibit dari tangkapan alam sebaiknya dilakukan penangkaran atau karantina dengan harapan cacing sutera mampu beradaptasi dengan habitat buatan sebelum disebar ke media didalam nampan.

b. Kotoran Ayam

Dalam budidaya cacing sutera dengan media nampan bertingkat penggunaan kotoran ayam sebagai substrat sangatlah penting.Tetapi jika kotoran ayam sulit ditemukan atau ketersediaanya tidak mencukupi maka 
dapat menggunakan kotoran sapi yang sudah dikeringkan.

c. Ampas Tahu

Ketersediaan ampas tahu di Kecamatan Belitang mencapai sekitar $855 \mathrm{Kg}$. Hal ini mendukung bagi pengembangan cacing sutera karena ampas tahu merupakan sumber makanan yang diperlukan oleh cacing sutera. Selain itu, harganya yang murah memudahkan bagi pembudidaya untuk menggunakan ampas tahu.

d. Dedak Halus

Dedak merupakan hasil dari penggilingan padi yang biasanya digunakan sebagai pakan ternak ataupun pakan ikan.Penggunaan dedak dalam budidaya cacing sutera tidak terlalu banyak dalam budidaya cacing sutera 400 wadah nampan memerlukan dedak halus sekitar $220 \mathrm{~kg}$.

3. Agroklimate

Tabel 12. Perbandingan Suhu dalam Budidaya Cacing

\begin{tabular}{llcc}
\multicolumn{1}{c}{ Sutera } & & \\
\hline No & Uraian & $\begin{array}{c}\text { Suhu di } \\
\text { Karangtejo } \\
\end{array}$ & $\begin{array}{c}\text { Suhu di Kec. } \\
\text { Belitang }\end{array}$ \\
& & $23-25{ }^{0} \mathrm{C}$ & $24-34{ }^{0} \mathrm{C}$ \\
\hline 1 & $\begin{array}{l}\text { Perbandingan } \\
\text { suhu }\end{array}$ & & \\
\hline
\end{tabular}

Sumber: Hasil Olahan Data Primer, 2018.

OKU Timur terletak pada ketinggian $48 \mathrm{~m} \mathrm{dpl} \mathrm{dan}$ Kecamatan Belitang memiliki iklim tropis basah, dengan variasi curah hujan $2.554-2.707,2 \mathrm{~mm} / \mathrm{tahun}$.Suhu berkisar antara $24-34{ }^{\circ} \mathrm{C}$ dengan tingkat kelembaban $54-$ $94 \%$.Jika dibandingkan dengan syarat hidup cacing sutera yaitu iklim yaitu tropis dengan suhu berkisar antara 25- 28 ${ }^{0} \mathrm{C}$. Maka cacing sutera dapat hidup di Kecamatan Belitang.hal ini diperkuat dengan cacing sutera mampu hidup dan dapat kita jumpai dihabitat aslinya yaitu diparit parit yang mengandung bahan organik di Kecamatan Belitang.

\section{BAB V. KESIMPULAN DAN SARAN}

\section{A. Kesimpulan}

1. Budidaya cacing sutera dengan nampan bertingkat dapat dikembangkan di Kecamatan Belitang

2. Biaya produksi yang dikeluarkan oleh petani pembudidaya cacing sutera dengan media nampan bertingkat di Desa Karangtejo Kecamatan Kedu Kabupaten Temanggung sebesar Rp 9.256.350 penerimaan sebesar Rp 18.977.000 dan pendapatan sebesar Rp 9.720.650 . Nilai R/C Ratio 2,05.

\section{B. Saran}

1. Pengembangan cacing sutera di Kecamatan Belitang harus segera dilakukan mengingat besarnya permintaan pasar terhadap cacing sutera dan masih mengandalkannya cacing sutera dari tangkapan alam. Sehingga akan membantu petani pembenih ikan dalam mencukupi kebutuhan cacing sutera.

2. Penelitian lebih lanjut mengenai potensi pakan cacing sutera yang ada di Kecamatan Belitang sehingga dapat mengetahui seberapa banyak cacing sutera yang dapat dikembangkan.

\section{DAFTAR PUSTAKA}

Anonim, 2014.Budidaya Cacing Sutra Untuk

Pakan.Ikan.Http://www.kompasiana.

Chumaidi dan Suprapto.1986. Populasi Tubifex sp. di Dalam Media Campuran Kotoran Ayam dan Lumpur Kolam.Bulletin. Panel Perikanan Darat 5 (2) :6- 11 Balitanwar Bogor.

Efendi, M. 2013. Budidaya Cacing Sutera Cara Moderen. Penebar Swadaya. Jakarta.

Efendi, M. 2014. Modul Pelatihan Budidaya Cacing Sutera Dengan Nampan Bertingkat (CSNB). Joglo Cacing : Semarang.

Gusrina, 2008. Budidaya Ikan Jilid 2. Direktorat Pengebangan Sekolah Menengah Kejuruan. Departeen Pendidikan Nasional

Ibrahim, Y. 2009. Studi Kelayakan Bisnis Jilid I. Rineka Cipta : Jakarta

Khairuman, Amri,K dan Sihombing, T. 2008. Peluang Usaha Budidaya Cacing Sutra. Agromedia Pustaka, Jakarta Selatan.

Mubyarto.1989. Pengantar Ekonomi Pertanian, CV. Yasaguna. Jakarta.

Priyambodo,K. dan Wahyuningsih,K. 2001. Budidaya Pakan Alami Untuk Ikan. Pustaka Setia. Yokyakarta. 64 Hal

Setiorini, FW.2008. Analisis Efisiensi Pemasaran Ikan Mas di Kecamatan Pagelaran Kabupaten Tanggamus Provinsi Lampung.(Skripsi) (tidak di publikasikan). Fakultas Perikanan dan Kelautan. Institute Pertanian Bogor. Bogor

Sjarkowi, F dan Marwan,S. 2004. Manajemen Agribisnis. CV. Baldad Grafiti Press. Palembang.

Soekartawi. 2006. Analisis Usahatani .Universitas Indonesia. Jakarta.

Sukirno, S. 2010. Modul Prosedur Pembelian, Barang penjualan dan Sistem Persediaan. PT Intan Pariwara : Jakarta

Supeni,T.Mintje,S.T. dan Talumewo,Y.P. 1994. Biologi.Erlangga :Jakarta 